\title{
A projeção de interesses em redes sociais de voluntariado
}

\author{
Marianna Taborda
}

\begin{abstract}
Resumo: Enquanto os dispositivos de vigilância das sociedades disciplinares eram centrados na correção, os dispositivos contemporâneos são voltados para a previsão, exercendo controle sem confinamento. Em busca de traçar perfis que antecipem ações, os dispositivos de vigilância coletam, registram e cruzam informações no ciberespaço. Sem a pretensão de investigar a interioridade do sujeito, a vigilância contemporânea projeta tendências $e$ interesses, a fim de incitar o consumo, prevenir doenças ou conter o crime. Servindo de recurso para diversos sites, como Amazon, Gmail e Last FM, a vigilância digital permite uma comunicação mais personalizada com os usuários e a organização do caos informativo. Tais dispositivos, por possibilitarem a elaboração de recomendações para diferentes perfis, também têm se mostrado valiosos para redes digitais de voluntariado. Indicações deste tipo são capazes de aproximar pessoas com interesses semelhantes e distribuir oportunidades de atuação voluntária, de forma direcionada, fomentando assim o voluntariado.
\end{abstract}

Palavras-chave: Vigilância, voluntariado, perfil computacional.

Abstract: While the surveillance devices of disciplinary societies were focused in correction, contemporaneous devices are focused in general forecasting. In order to create profiles that anticipate actions, the surveillance devices gather, register and cross information in cyberspace. Contemporaneous surveillance seeks to forecast trends and interests and has no pretention to investigate in depth the inner reality of the individual. This is accomplished with the purpose to foster the sale of goods, prevent illnesses, or diminish crime rates. Surveillance devices are used as a resource in several sites, allowing a more personalized communication with users. Because these devices facilitate the elaboration of recommendations for varying profiles, they have also proven invaluable for social volunteer networks. Indications such as these make it possibile to connect people with similar interests and make volunteering opportunities directly available, therefore fostering volunteerism itself.

Keywords: Surveillance, volunteerism, computer profiles. 
Résumé: Tandis que les dispositifs de sécurité dans les sociétés disciplinaires était centrés dans la correction, les dispositifs numériques contemporains sont plutôt tournés vers la prévision. Dans le but de tracer des profils pour prévoir des actions, les dispositifs de surveillance informatique collectent, enregistrent et croisent des informations dans le ciberespace. La vigilance contemporaine projette, sans avoir la prétention de rechercher l'intériorité du sujet, des tendances et des intérêts, à fin d'inciter la consommation, prévenir des maladies ou contenir la criminalité. Cela est donc un moyen pour des sites divers, la surveillance informatique qui permet une communication plus personnalisée avec les utilisateurs, et, par conséquent, l'organisation du chaos informatif. Puisque ces dispositifs, rendent possible l'élaboration de recommandations pour les plus différents profils, ils sont utiles pour des réseaux sociaux de volontariat. Ces indications sont capables d'approcher des personnes avec des intérêts semblables et de distribuer des opportunités d'action volontaire, de façon ciblée, en stimulant ainsi le volontariat.

Mots-clés: Surveillance, volontariat, profil numérique.

Resumo: Mientras que los dispositivos de vigilancia de las sociedades disciplinares estaban centrados en la corrección, los dispositivos contemporáneos están enfocados en la previsión. Con el fin de trazar perfiles que anticipen acciones, los dispositivos de vigilancia digitais, recogen, registran y cruzan informaciones. Sin la pretensión de investigar la interioridad del sujeto, la vigilancia contemporánea proyecta tendencias $e$ intereses, con el fin de incitar al consumo, prevenir enfermedades o evitar el crimen. Sirviendo de recurso en distintos espacios de Internet, la vigilancia digital permite una comunicación mas personalizada con los usuarios y consecuentemente la organización del caos informativo. Tales dispositivos, al posibilitar la elaboración de recomendaciones para diferentes perfiles, también han resultado valiosos para las redes sociales de voluntariado. Indicaciones de este tipo permiten acercar personas con intereses semejantes y distribuir oportunidades de actuación voluntaria, de forma direccionala, fomentando así el voluntariado.

Palabras clave: Vigilancia, voluntariado, perfil computacional. 


\section{A previsão no ciberespaço}

Situadas por Foucault nos séculos XVIII, XIX e XX, as sociedades disciplinares foram substituídas por novas forças, que entraram em curso a partir da Segunda Guerra Mundial. A sociedade de controle inaugurou um novo regime, cujo funcionamento não se baseia mais em meios de confinamento, como escola, prisão, fábrica e hospital, mas na comunicação instantânea e no controle contínuo de indivíduos comuns - possível de ser exercido em meio aberto. "Nas sociedades de disciplina não se parava de recomeçar (da escola à caserna, da caserna à fábrica), enquanto nas sociedades de controle nunca se termina nada” (DELEUZE, 1992, p. 221).

Se antes o controle era centrado em ambientes fechados, modelos arquitetônicos e no olhar do outro, hoje está interiorizado pelos indivíduos, que se sentem e, na maioria das vezes são, observados constantemente. O olhar do outro, que tinha função superegóica de repressão, foi assimilado como autocontrole. A intimidade passa a perceber este olhar não tanto como interdição, mas como um mecanismo de valorização do observado - o valor aumenta, na medida em que o sujeito consegue reter atenção dos outros.

Assim, quando a vida privada não só interioriza como convoca o olhar do outro para que o indivíduo se sinta relevante no mundo, a vigilância também muda de papel. Não somente é aceitada, como muitas vezes requisitada, seja para satisfazer o ego, buscar segurança, atender a fins mercadológicos, preventivos ou para trazer outras vantagens.

No caso da livraria virtual Amazon, o usuário pode se deparar com a indicação de um livro que seja relevante para ele, sem que nunca tenha ouvido falar naquele produto. Tudo porque o monitoramento digital permite que o sistema tenha informações suficientes para a previsão de interesses, de acordo com cada perfil. De modo semelhante, ocorrem as indicações de músicas do Last FM e os anúncios do Gmail. Como será visto a seguir, a vigilância contemporânea tem mecanismos de controle que não seguem os mesmos princípios corretivos dos métodos disciplinares.

Os dispositivos de vigilância das sociedades disciplinares são relacionados por Foucault ao Panóptico de Bentham, modelo arquitetônico circular, onde há celas 
em formato de anel e uma torre no centro. Jogos de luz fazem com que os presos se sintam observados constantemente, sem conseguir ver se há ou não algum guardião presente na torre. "O Panóptico é uma máquina de dissociar o par ver-ser visto: no anel periférico, se é totalmente visto, sem nunca ver, na torre central, vê-se tudo, sem nunca ser visto" (FOUCAULT, 1983, p. 167). De acordo com o autor, o efeito mais relevante do panóptico é "a indução de um estado consciente e permanente de visibilidade, que assegura o funcionamento automático do poder" (FOUCAULT, 1983, p. 166). A sensação de ser observado é contínua, mesmo que a vigilância não seja permanente de fato.

Por dispositivo, termo que aparece em Foucault nos anos 70, entende-se:

Operadores materiais de poder, ou seja, técnicas, estratégias, formas de sujeição, acionadas pelo poder. (...) um dispositivo é um conjunto absolutamente heterogêneo, comportando discursos, instituições, instalações arquiteturais, decisões regulamentares, leis, medidas administrativas, enunciados científicos, proposições filosóficas, morais, filantrópicas, em suma: o dito e o não dito (...) O dispositivo propriamente é a rede que pode se estabelecer entre esses elementos (REVEL, 2002, pp. 24-25).

De acordo com Ieda Tucherman, ao discorrer sobre Foucault, um dispositivo não é um equipamento e, sim, um regime de fazer ver e fazer dizer, constituidores de sujeitos. "O poder se reconhece nas positividades que produz, não sendo na censura ou na violência que ele se afirma" (TUCHERMAN, 2005, p.42). O poder, ao invés de dizer não ou de reprimir, intervém nas ações possíveis. Orienta a escolha do indivíduo, entre as várias formas de se alimentar, se relacionar e consumir, por exemplo.

Temos que deixar de descrever sempre os efeitos de poder em termos negativos: ele exclui, reprime, recalca, censura, abstrai, mascara, esconde. Na verdade, o poder produz; ele produz realidade; produz campos de objetos e rituais de verdade. $\mathrm{O}$ indivíduo e o conhecimento que dele se pode ter se originam dessa produção (FOUCAULT, 1983, p. 161).

Com a função de prever, em vez de corrigir e punir, a vigilância contemporânea coleta, registra e cruza informações, a fim de traçar perfis que antecipem ações e possam gerar estratégias, de acordo com o fim que se quer atingir. Misturados com o próprio ciberespaço, os dispositivos de vigilância eletrônicos não 
confinam nem imobilizam os indivíduos para discipliná-los. O que interessa é prever potencias atitudes, seja para conter as pessoas, evitando crimes, prevení-las, alertando para doenças, seja para incitá-las, como no caso do consumo, da publicidade e do marketing. Considerando os dispositivos modernos, há diferenças notáveis:

A incidência de visibilidade sobre o indivíduo não quer curar ou reformar o criminoso, o doente físico ou mental, mas sim impedir o crime, prevenir a doença ou minimizar seus riscos. Ou seja, o foco de intervenção não é mais a alma, a interioridade, o psiquismo, mas o comportamento, o campo de ações exteriores e visíveis (BRUNO, 2004, p.117).

Não se trata mais de decifrar históricos pessoais nem de revelar uma interioridade. No lugar do ritual do exame e seus processos hermenêuticos, entram os perfis computacionais e seus procedimentos algorítmicos e estatísticos. Ao contrário de buscar conhecer o indivíduo em sua singularidade e totalidade, a vigilância digital analisa ações registradas no ciberespaço, gerando informações que correspondem a uma parte da existência dele, como paciente, consumidor, profissional. A intenção não é construir um saber sobre determinado sujeito, mas "utilizar um conjunto de informações pessoais para agir sobre outros indivíduos. (...) Este saber é ao mesmo tempo controle, pois antecipa o que cada um é, o que pode fazer e o que pode escolher" (BRUNO, 2006, p.156).

A vigilância contemporânea aproxima-se dos indivíduos e monitora suas atividades durante as interações, de forma interligada com as trocas informacionais. Pouco importa mergulhar na particularidade de alguém para reformá-la, mas de combinar traços, cruzar características, interesses e comportamentos, a fim de formar um banco de dados e formar perfis que assumam a função de oráculos. Tratase de:

Uma vigilância que se exerce menos com o olhar do que com sistemas de coleta, registro e classificação da informação; menos sobre corpos do que sobre dados e rastros deixados no ciberespaço; menos com o fim de corrigir e reformar do que com o fim de projetar tendências, preferências, interesses (BRUNO, 2006, p.153).

Nos estudos de Foucault sobre os dispositivos de vigilância na Modernidade, são encontrados dois aspectos fundamentais: o olhar, simbolizando as táticas de ver e ser visto, e a informação sobre os indivíduos, envolvendo técnicas de coleta, registro e 
classificação. Não basta, portanto, vigiar, mas produzir conhecimento sobre os vigiados e documentá-lo.

$\mathrm{Na}$ escola, no exército, na fábrica, nos hospitais, nas prisões, os sujeitos são, ao mesmo tempo, olhados e objetivados através de exames que irão constituir registros dos seus dados individuais (suas competências, evoluções, falhas, sintomas, características físicas e psíquicas, biografia etc.) e organizar campos comparativos que permitam classificar, formar categorias, estabelecer médias, fixar normas (FOUCAULT, 1983, p. 169).

$\mathrm{Na}$ atualidade, com os dispositivos de vigilância digital, esta capacidade de coleta, registro e processamento de informações sobre indivíduos aumentou consideravelmente. "Indivíduos são alvos da vigilância mais do que em qualquer outro ponto da história" (BOGARD, p. 75, 1996). Mas a maior quantidade de pessoas vigiadas não implica, simplesmente, na ampliação do modelo panóptico. Mais do que isso, surgem mudanças estruturais.

De acordo com Mark Poster, o banco de dados funcionaria como um superpanóptico, que atinge uma maior quantidade de vigiados, sem precisar recorrer a construções arquitetônicas, complexos sistemas administrativos e organizações burocráticas. A vigilância eletrônica e simulada toma lugar da geográfica e presencial, com muros e guardas. "Ao contrário do panóptico, o superpanóptico pode atuar quase sem esforço. A capilaridade do poder, percebida por Foucault nos espaços das sociedades disciplinares, é bem mais efetiva atualmente" (LYON e ZUREIK, p.184).

O olhar tem sua importância relativamente reduzida nos dispositivos de vigilância eletrônicos, que não exigem a presença simultânea dos corpos do observador e observado, quanto menos do início ao fim. Na maior parte das vezes, por sinal, os vigiados são dados, rastros, e não, pessoas. De modo geral, os dispositivos de vigilância digital têm três elementos centrais: a informação (como elemento-base), os bancos de dados e os perfis computacionais (profiles). A mesma tecnologia que permite a interação entre os indivíduos e possibilita trocas no anonimato, muitas vezes, coincide com os próprios sistemas de identificação, coleta e registro de dados.

Diversos sites recorrem à vigilância digital para antecipar possíveis comportamentos de seus usuários, como a compra de determinado produto ou o interesse por algum anúncio. A Amazon indica produtos para cada pessoa, de acordo 
seu comportamento de compra e busca no site; já o Gmail se baseia no conteúdo das mensagens que circulam pela caixa postal para anunciar links relacionados; o Last FM sugere músicas e aproxima pessoas, com gosto musical semelhante.

Antecipar desejos e preferências, na forma de ofertas, é um dos objetivos primordiais destes agentes. Os consumidores recebem indicações de produtos que eles nem sequer haviam pensado ou sabiam que existiam. Tais ofertas têm a proposta de serem individualizadas, de acordo com o perfil.

\section{A performance dos perfis}

Perfil, ou profile em inglês, significa pré-registro ou pré-ordenação. A previsão dos perfis mostra-se efetiva não tanto pela sua precisão em antecipar o futuro, mas pelo fato de que a antecipação acaba influenciando as escolhas e atitudes do presente, concretizando aquilo que havia sido antecipado. Estas antevisões não são, portanto, nem verdadeiras nem falsas. Funcionam na ordem da simulação e da performance.

Os perfis computacionais são entendidos não apenas como tecnologias de vigilância, mas como uma espécie de vigilância que antecipa a vigilância, uma tecnologia de observação antes do fato. Um perfil, como o próprio nome sugere, é um tipo de préordenação, que organiza várias formas de informação para para mapear combinações e casos excepcionais (BOGARD, 1996, p.27)

Como qualquer dispositivo de vigilância, os contemporâneos afetam a produção de identidades e subjetividade. As identidades projetadas em bancos de dados, na forma de perfis computacionais, não refletem uma personalidade préexistente ou a exposição de uma realidade prévia. Tampouco prevêem um futuro certo. São como duplos digitais e simulações, que efetuam uma realidade e uma identidade, na medida em que a antecipam.

Ao aceitar a recomendação de uma oferta pela qual não esperava anteriormente, o indivíduo reforça previsões a respeito dele e de pessoas com características similares nos bancos de dados. Neste sentido, os perfis operam quase como oráculos. Não há preocupação com a verdade do indivíduo, mas com a performatividade. Ou seja:

O perfil é menos um retrato fiel que representa, neste caso, a verdade dos desejos inerentes ao consumidor do que uma simulação 
deste desejo, que, ao se anunciar, tem uma efetividade performativa e proativa, fazendo passar à realidade o que era apenas uma possibilidade, uma potencialidade (BRUNO, 2006, p.156).

Assim como serve de recurso para o Gmail, a Amazon e o Last FM relacionarem-se com seus usuários, por meio de recomendações do sistema, a vigilância digital também pode contribuir para melhorar a performance de redes sociais de voluntariado. Unir voluntários com perfis semelhantes, por meio de indicações do sistema, ou recomendar oportunidades de atuação voluntária, de acordo com o interesse de cada usuário, são estratégias capazes de estimular encontros na rede e, conseqüentemente, incentivar a cooperação. Assim como sistemas de reputação, as recomendações ajudam a organizar o caos informativo, onde os usuários nem sempre conseguem encontrar aquilo que desperte seu interesse.

Boas idéias podem se afogar em um oceano de mediocridade, quando o excesso de informação esfumaça a qualidade. Esta não é apenas uma questão de perda de tempo - muitos têm afirmado que muitas ofertas com informações irrelevantes diminuem a capacidade individual e coletiva de funcionar efetivamente. $\mathrm{O}$ que pode ser feito: desenhar sistemas distribuídos de reputação tem o potencial de facilitar a busca de oportunidades, idéias, relacionamentos, bens culturais e serviços ${ }^{1}$ (MASUM, ZHANG).

\section{O voluntariado em rede}

Como a conexão é um dos elementos centrais das redes de relacionamento virtuais, nada mais natural do que estes ambientes serem reconhecidos como espaços propícios para o fortalecimento do voluntariado - prática extremamente vinculada à informação e cooperação. Por meio de redes digitais de voluntariado, pessoas que querem ser voluntárias podem encontrar outras que precisam de apoio. Integrados entre si, indivíduos ganham ferramentas e autonomia para publicar ou buscar oportunidades de atuação voluntária, escrever relatos inspiradores de suas experiências, assim como divulgar as ações sociais da qual fazem parte.

Segundo a Lei do Serviço Voluntário², por voluntariado entende-se:

1 Traduzido por mim, do Manifesto for the Reputation Society: www.firstmonday.org/issues/issueg 7/masum/index.html\#author. 2 LEI DO SERVIÇO VOLUNTÁRIO, número 9.608, Diário Oficial da União, 18/02/98. 
Atividade não remunerada, prestada por pessoa física a entidade pública de qualquer natureza ou instituição privada de fins não lucrativos, que tenha objetivos cívicos, culturais, educacionais, científicos, recreativos ou de assistência social, inclusive, mutualidade.

A Declaração Universal do Voluntariado3, apresentada em 1990 pela IAVE (Internacional Association for Volunteer Effort), define o voluntariado da seguinte maneira:

- É baseado numa escolha e motivação pessoal, livremente assumida;

- É uma forma de estimular a cidadania ativa e o envolvimento comunitário;

- É exercido em grupos, geralmente inseridos em uma organização;

- Valoriza o potencial humano, a qualidade de vida e a solidariedade;

- Dá respostas aos grandes desafios que se colocam para a construção de um mundo melhor e mais pacífico;

- Contribui para a vitalidade econômica, criando empregos e novas profissões.

As redes digitais de voluntariado, ao facilitarem a interação em grupo, tanto de pessoas quanto de instituições, se apresentam como alternativas para a dependência de intermediações formais - tais como ocorrem nas entidades, que disponibilizam fichas e treinamentos para o preenchimento de vagas de trabalho voluntário. É valioso estimular o protagonismo dos indivíduos para que eles se engagem como voluntários de forma autônoma, pois existe uma discrepância entre o número de pessoas dispostas a atuarem como voluntárias (cerca de 53 milhões, no Brasil) e a quantidade de organizações para recebê-las (280 mil, aproximadamente).

Tal comparação utiliza dados da pesquisa ${ }^{4}$ Doações e Trabalho Voluntário no Brasil, publicada em 2000. De acordo com o estudo, nada menos do que 60,5\% dos adultos brasileiros estariam dispostos a "trabalhar como voluntário se soubesse

3 Convocados pela INTERNATIONAL ASSOCIATION FOR VOLUNTEER EFFORT (IAVE), voluntários de todo o mundo aprovaram, em 1990, a Declaração Universal do Voluntariado. O documento foi inspirado na Declaração Universal dos Direitos Humanos, de 1948, e na Convenção dos Direitos da Criança, de 1989.

4 "(...) foi utilizada uma amostra estratificada e representativa da população brasileira com 18 anos ou mais, que vivem em cidades de mais de 10.000 habitantes, contando com um total de 1.200 entrevistas em domicílios." (LANDIM; SCALON, op. cit., p. 22 apud AYRES, 2003) 
onde poderia ajudar" (LANDIM; SCALON apud AYRES 2003, p.12). Naquele ano, segundo dados do Instituto Brasileiro de Geografia e Estatística (IBGE), a população brasileira - hoje calculada em 187.320.233 habitantes - somava 169.799.170, sendo $64,55 \%$ representados por pessoas entre 15 e 64 anos e $5,85 \%$ por maiores de 65 anos 5 .

Supondo que a disposição dos brasileiros de ajudar não tenha se alterado consideravelmente desde então, vale reconhecer um engasgo, levantado na dissertação de mestrado Informação, Voluntariado e Redes Digitais , em consideração à pesquisa citada:

Este percentual $(60,5 \%)$ corresponde a um contingente de 53 milhões de pessoas, aproximadamente. Mas se colocarmos este dado ao lado do número de instituições sociais formalmente registradas no Brasil - algo em torno de 200 mil - temos um gargalo. Mesmo sabendo da limitação que simples números trazem à análise de um ambiente social complexo como este, não podemos ignorar a discrepância entre estes dois dados (53 milhões de potenciais voluntários / 200 mil ONGs) e verificar que há aqui um grande estrangulamento: em uma conta simples, percebe-se que a perspectiva organizacional não é suficiente para o desenvolvimento do voluntariado no Brasil e é preciso apresentar outras visões e ampliar conceitos, limites e alternativas para que esse potencial se desenvolva (AYRES, 2003, p.12).

Apresentando dados atualizados, o estudo As Fundações Privadas e as Associações Sem Fins Lucrativos no Brasil6 revela que, em 2002, o país abrigava 276 mil fundações e associações sem fins lucrativos. Torna-se clara, portanto, a relevância de fornecer recursos para que os indivíduos possam agilizar sua adesão ao voluntariado. $\mathrm{O}$ aumento da conectividade entre pessoas que querem ajudar e que precisam de apoio, sem excluir a participação de instituições formais, mostra-se como alternativa eficiente. Neste aspecto, as redes digitais mostram-se como terreno fértil para a cooperação.

5 Dados coletados em http://www.ibge.gov.br/brasil_em_sintese/default.htm 6 Lançada em dezembro de 2004, pelo Instituto de Pesquisa Econômica Aplicada (Ipea) e o Instituto Brasileiro de Geografia e Estatística (IBGE), em parceria com a Associação Brasileira de Organizações Não Governamentais (Abong) e o Grupo de Institutos, Fundações e Empresas (Gife). Acessível em: www.abong.org. 
Foi a partir destas constatações que surgiu a rede de voluntariado V2V (Volunteer-to-Volunteer) do Portal do Voluntário7, onde estão reunidos cerca de 40 mil usuários, entre voluntários e organizações. Ali, os próprios integrantes podem oferecer e procurar oportunidades de trabalho voluntário e doação, em formas de posts, além de apresentarem suas causas sociais prediletas (meio ambiente, educação, saúde, esporte, consumo consciente, entre outras), públicos de interesse (infância, terceira idade, adulto e juventude) e seus perfis como voluntários (habilidades, cidade de origem etc).

Nascido em 5 de dezembro do 2000, com a missão de fortalecer a causa do voluntariado no Brasil, o Portal do Voluntário surgiu de uma iniciativa do Programa Voluntários da Comunidade Solidária (1997), da Rede Globo de Televisão, Globo.com e IBM Brasil. Quatro anos depois, desenvolveu e lançou a ferramenta V2V, a fim de ampliar o alcance do voluntariado no país.

A tecnologia V2V, inspirada no padrão P2P (Peer-to-Peer), foi concebida na dissertação de mestrado apresentada à UFRJ Informação, Voluntariado e Redes Digitais, citada anteriormente. Esta ferramenta, além de ser disponibilizada gratuitamente para qualquer usuário, é utilizada em redes de voluntariado corporativo, cuja criação e manutenção possibilitam a sustentabilidade do projeto. Cada rede corporativa de voluntariado ${ }^{8}$ é desenvolvida de modo customizado pelo Portal do Voluntário para programas de empresas como HSBC, Vale do Rio Doce, Itaú, Embratel, Embraer, CPFL Energia, ABN Amro Bank, Vivo, Alcoa e Nike. Todas somam cerca de 10 mil integrantes, entre funcionários e convidados. Entre as instituições sociais que utilizam o V2V estão a Rede Social São Paulo, o Portal da Universidade Solidária e do Centro de Voluntariado de Natal.

Após ter se consolidado no Brasil, o Portal do Voluntário firmou uma parceria com a rede de voluntariado Haces Falta ${ }^{9}$, da Espanha, para criação do V2V Network, uma rede de voluntariado global, que conquistou apoio financeiro e

\footnotetext{
$7 \quad$ www.portaldovoluntario.org.br

8 Todos os endereços estão disponíveis em:

http://www.portaldovoluntario.org.br/site/pagina.php?idconteudo=285

9 www.hacesfalta.es
} 
intelectual da Omidyar Netwok ${ }^{10}$ (criada pelo fundador do Ebay). Preparando-se para mudar de escala, o V2V se deparou com o desafio de evitar o caos informativo da rede, neste universo que se ampliou. Com este fim, busca estratégias para que os encontros de interesses aconteçam na rede, de modo mais eficiente possível, sem intervir na liberdade de publicação nem na descentralização. Entre elas, o envio de recomendações do sistema aos usuários, de acordo com seus perfis.

\section{A união de interesses}

Até o momento, o Portal do Voluntário havia investido na análise dos dados de evolução das redes V2V, como crescimento da quantidade de usuários, número de oportunidades publicadas e ações postadas, em períodos anuais, mensais e diários. Cada projeto possui um gerente que analisa as informações da rede e elabora campanhas de newsletter para se comunicar com diferentes tipos de usuários. Um ambiente restrito, chamado Inteligência $\mathrm{V} 2 \mathrm{~V}$, fornece dados online sobre a rede, assim como gráficos de evolução e perfil - número de usuários ou ações por estado, por causas ou públicos de interesse.

Integrado ao funcionamento da rede, mas sem ser acessível aos usuários, o Inteligência $\mathrm{V} 2 \mathrm{~V}$ também gera listas de voluntários, por tipo de público - levanta, por exemplo, quem são os mais ativos, quem não tem foto no perfil, quem nunca ofereceu oportunidades de voluntariado ou aqueles que não se logam há mais de 2 meses. A partir destas listas, o gerente de cada rede V2V envia campanhas direcionadas por email a usuários que optam por receber boletins informativos.

Com o objetivo de estimular a publicação de oportunidades, facilitar o encontro de interesses e incentivar a interação na rede, as campanhas por e-mail nem sempre geram resultados satisfatórios. Por meio da análise da quantidade de mensagens abertas e links clicados, concluiu-se que newsletters não são os melhores meios para atingir tais fins, já que os destinatários muitas vezes nem sequer lêem as mensagens, mergulhados por SPAMs e pelo excesso de informação da Internet, de forma geral.

$10 \quad$ www.omidyar.net 
A partir disso, percebeu-se que a aproximação dos usuários com seus interesses deveria ser feita não por meio de mensagens exteriores ao sistema, gerenciadas por uma pessoa que relacionasse os dados restritos do Inteligência V2V. A melhor opção seria fornecer recomendações do sistema, por meio da própria ferramenta, disponibilizando indicações de pessoas, oportunidades e conteúdos, diretamente na página de cada usuário, de acordo com seu perfil.

O primeiro passo, depois de tal percepção, foi a criação do botão “Oportunidades para o seu Perfil”, adicionado ao blog de cada integrante da rede. Ao clicar no botão, o usuário encontra uma lista de oportunidades de voluntariado, postadas por outras pessoas e selecionadas pelo sistema, de acordo com os interesses descritos por cada voluntário. A busca por oportunidades faz um cruzamento automático entre o perfil do usuário e as oportunidades disponíveis na rede, de acordo com causas, cidade e público de interesse. Oferece, assim, oportunidades que têm o potencial de interessá-lo, segundo as informações que ele mesmo especificou no perfil.

Os passos seguintes desta mudança de abordagem estão sendo planejados para a próxima versão da ferramenta V2V. Buscando aplicar todo o aprendizado obtido nos últimos 4 anos de existência da rede, a nova versão prevê o uso de tags para a flexibilização de categorias de interesse, a utilização de um sistema de reputação para que o usuário eleja informações preferenciais, a melhoria do sistema de busca e a disponibilização de recomendações do sistema aos usuários, visíveis na própria ferramenta. Neste último caso, os integrantes da rede poderão ver, em suas páginas, galerias com recomendações do sistema: pessoas com interesses semelhantes aos seus, oportunidades de acordo seu perfil e ações que contam com a participação de seus amigos.

A vigilância digital assume importância fundamental para a rede de voluntariado $\mathrm{V} 2 \mathrm{~V}$, na medida em que serve de ferramenta para a recomendação de oportunidades de atuação voluntária, direcionadas a cada perfil. As indicações do sistema podem aproximar voluntários de outros voluntários (ou instituições) que se mobilizem por causas semelhantes. Partindo da hipótese de que estas orientações ajudam a organizar o caos informativo na rede, espera-se que aconteçam mais 
encontros com potencial de culminarem em ações sociais. Deste modo, a causa do voluntariado, como um todo, acaba sendo promovida.

Buscando a união de interesses, a análise de perfis e bancos de dados serve para auxiliar no alcance de outro objetivo da rede V2V: enviar recomendações que tornem seus usuários mais participativos e, conseqüentemente, estimulem o protagonismo social. Identificar diferentes perfis de usuários na rede pode resultar em um melhor aproveitamento das capacidades de cada participante, por meio de mensagens personalizadas a cada tipo de público.

Auxiliando na formação de redes pessoais, as recomendações podem servir de meio para que se chegue ao cenário ideal: em que o indivíduo se torne tão ambientado na rede que deixa de ser somente um consumidor de oportunidades de voluntariado, passando a criar e distribuir oportunidades de atuação para outros integrantes.

Visibilizar exemplos de ação de forma coerente com os interesses demonstrados por cada voluntário serve de estímulo para a cooperação e para o fortalecimento de relações de proximidade. Ao analisar a relação de vizinhança e cooperação das células, Steven Johnson aborda processos colaborativos em rede, demostrando a importância da ação exemplar:

As células baseiam-se fundalmentalmente no código de DNA para seu desenvolvimento, mas também precisam de um sentido de lugar para cumprir sua tarefa. Na verdade, o código é totalmente inútil sem a habilidade da célula para determinar seu lugar no organismo total, uma façanha conseguida graças à estratégia de prestar atenção às vizinhas. (...) A célula olha em volta para as vizinhas e vê que todas estão empenhadas na construção de um tímpano ou de uma válvula do coração, o que a leva por sua vez a trabalhar na mesma tarefa (JOHNSON, 2003, p.63).

Também no caso de redes sociais de voluntariado, esta perspectiva de vizinhança deve ser estimulada. Tornar visíveis exemplos de ação que possam mobilizar outros voluntários é incentivar a adesão de mais pessoas à causa. 


\section{BIBLIOGRAFIA:}

AYRES, B. Informação, Voluntariado e Redes Digitais. Dissertação de Mestrado, Programa de Pós-Graduação em Ciência da Informação - convênio entre a Escola de Comunicação da Universidade Federal do Rio de Janeiro (ECOUFRJ), Instituto Brasileiro de Infomação em Ciência da Tecnologia (IBICT) e Conselho Nacional de Desenvolvimento Científico (CNPq). Rio de Janeiro, 2003.

BOGARD, W. The simulation of surveillance: Hypercontrol in telematic societies. Cambridge: Cambridge University Press, 1996.

BRUNO, F. Dispositivos de vigilância no ciberespaço: duplos digitais e identidades simuladas. Revista fronteira, São Leopoldo/RS, v. VIII, p. 152-159, 2006.

. Quem está olhando? Variações do público e do privado em weblogs, fotologs e reality shows. Contemporânea Revista de Comunicação e Cultura, Salvador, v. 3, n. 2, p. 53-70, 2005.

. Máquinas de ver, modos de ser: visibilidade e subjetividade nas novas tecnologias de informação e de comunicação.. Revista da FAMECOS, Porto Alegre, v. 24, p. 110-124, 2004.

Entre Aparecer e Ser: tecnologia, espetáculo e subjetividade contemporânea. Intexto, Porto Alegre, v. 11, p. 1-10, 2004b.

DELEUZE, G. Conversações. Rio de Janeiro: Ed. 34, 1992. FOUCAULT, M. Vigiar e Punir. Petrópolis: Vozes, 1983.

JOHNSON, Steven. Emergência - A Dinâmica de Rede em Formigas, Cérebros, Cidades e Softwares. Rio de Janeiro: Jorge Zahar, 2003.

LEVIN, T. Y., Frohne, U. \& Weibel, P. (Orgs.) CTRL [SPACE]: Rhetorics of Surveillance from Bentham to Big Brother. MIT Press, 2002.

LYON, D. Surveillance as Social Sorting: Privacy, Risk, and Digital Discrimination. Routledge, 2002.

MASUM, Hassan e ZHANG, Yi-Cheng Zhang. Manifesto for the Reputation Society. Em www.firstmonday.org/issues/issueg 7/masum/index.html\#author.

REVEL, J. Vocabulaire de Foucault. Paris; Ellipses, 2002.

TUCHERMAN, I. "Michel Foucault, hoje, ou ainda: do dispositivo de vigilância ao dispositivo de exposição da intimidade" in: Revista Famecos, n. 27. Porto 